\title{
Articles
}

\section{Anti-Selective Dihydroxylation Reactions of Monosubstituted and (E)-Ester Conjugated Allylic Amines by Bulky Alkyl Groups}

\author{
Jongho Jeon, So-Hee Kim, Jong Hyup Lee, Joon Seok Oh, Doh Yeon Park, and Young Gyu Kim \\ Department of Chemical and Biological Engineering. Seoul National Cniversin. Seoul 151-74t. Korea \\ ${ }^{*}$ E-mail: vghimashu.ac.kr \\ Received Jamary 31, 2009, Accepted March 11, 2009
}

\begin{abstract}
The $\mathrm{OSO}_{4}$-catalyzed dihydroxylations of a monosubstituted allylic amine and $\gamma$-amino- $\alpha, \beta$-unsaturated $(E)$-esters with bulky alkyl groups showed a high anti-selectivity. Since the acyclic conformation of $N$-acyloxy protected ally lic amines was efficiently controlled by a bulhy $t$-Bu or $\mathrm{OBO}$ ester group, the ant diastereoselectivity of $>12.5: 1$ was obtained without applying a chiral reagent. The synthetic utility of the present method was demonstrated by a stereoselective and efficient sy'nthesis of an $\alpha$-glucosidase inhibitor 15 from commercially available $N-C b z-L-$ serine 6 in 11 steps and $31 \%$ yield.
\end{abstract}

Key Words: Așymmetric ș̣nthesis. Amino alcohols. Dihydroxỵlations. OBO eșter

\section{Introduction}

A dilydroxylation reaction of chiral allylic amines with $\mathrm{OsO}_{4}$ is one of the convenient methods to produce an amino alcohol moiety that is a key motif present in numerous bioactive natural products and synthetic compounds. In the case of crclic allylic amines. the desired facial selectivity of the dihydroxylation reactions could be effectively produced by substrate- or chelation-controlled reactions. ${ }^{2}$ However the acyclic allylic amines with widely used $\mathrm{N}$-acyl or $\mathrm{N}$-acy loxy protecting groups resulted in low or often inconsistent selectivity due to their flexible acyclic conformation. ${ }^{3}$ The wellestablished Sharpless asymmetric dilydroxylation gave mixed results in several cases.

We have been interested in the diastereoselective dilydroxỵlation reactions of acyclic allỵlic amines by controlling acyclic conformation of the substrates. Enhanced stereochemical results have been achieved by using the $N$-diarylmethylene or $\mathrm{N} N$-diBoc group ${ }^{5}$ instead of the $\mathrm{N}$-acyloxy protecting groups. Since these protecting groups efficiently controlled the acyclic conformation of the allylic amines. the high diastereoselectivity was obtained without the need of chiral reagents. In a few cases. the stereoselectivities obtained from the above methods were better than those of the Sharpless asymmetric dihydroxy lation.

However, the above methods have a disadvantage that the readily available and versatile $N$-protecting groups such as an $\mathrm{N}$-Boc or $\mathrm{N}$-Cbz group cannot be used. Here. we would like to report that a bulky alkyl group of chiral allylic amines can be utilized to control effectively their acyclic conformation and a high and useful selectivity could be achieved even with the versatile and widely used $\mathrm{N}$-Boc or $\mathrm{N}$-Cbz group.

In our previous report. the $\mathrm{OsO}_{4}$-catalyzed dihy droxylations of $\gamma$-amino- $\alpha, \beta$-unsaturated $(E)$-esters with the $N$-diarylmethylene group gave consistent anti-selectivity (6.7:1 -
19:1). ${ }^{5 \mathrm{~b}}$ The selectivities increased as the alkyl group of the substrates became larger. The similar stereochemical trend was observed by Reetz and coworkers with the $N$-Boc derivatives of the $\gamma$-amino- $\alpha, \beta$-unsaturated $(E)$-esters. ${ }^{3 \mathrm{c}}$ They reported the highest anti-selectivity of $c a .4 .3: 1$ when the alkyl group was an i-Pr group. The increased $a n t$-selectivities (3.7:1 $7: 1)$ were also observed with the 1 -dianylmethylene derivatives of the monosubstituted allylic anines. ${ }^{\text {5a }}$ Thus. we envisioned that a bulkier alkyl group such as a tert-alkyl group in both $\gamma$ anino- $\alpha, \beta$-unsaturated $(E)$-esters and monosubstituted allylic amines would induce higher anti-selectivity even with the popular $X$-protecting groups and without any chiral reagents.

\section{Results and Discussion}

First. we have examined the $\mathrm{OSO}_{4}$-catalyzed dihydroxylation of the $X-B o c$ derivatives of a monosubstituted allylic amine and $\gamma$-amino- $\alpha . \beta$-unsaturated esters that have a tert-Bu group in the alkyl chain (Table 1). The starting compounds la-c were prepared from the Wittig olefination of the corresponding amino aldehyde that was derived from an oxidation of commercially available $\mathrm{N}$-Boc-tert-leucinol. The dihydrosylations were conducted with catalytic amount of $\mathrm{OsO}_{4}$

Table 1. Dihydrosylations of allylic amines with a $t-B u$ group

\begin{tabular}{|c|c|c|c|c|c|}
\hline$Q \mathrm{CH} \mathbb{N}_{\equiv}$ & $\begin{array}{l}\text { 1) } \mathrm{OsC} \\
\text { 2) } \mathrm{Ac}_{2}\end{array}$ & $\begin{array}{l}\text { NMO } \\
T E A, D K\end{array}$ & $\mathrm{BocHN}$ & $R^{1}$ & 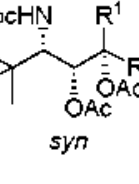 \\
\hline Substrate & Product & $\mathrm{R}^{\mathrm{l}}$ & $\mathrm{R}^{2}$ & anti:syn & Yield (\%) \\
\hline la & $2 a$ & $\mathrm{H}$ & $\mathrm{CO}_{2} \mathrm{Me}$ & $>20: 1$ & 83 \\
\hline 1b & $2 b$ & $\mathrm{CO}_{2} \mathrm{Me}$ & $\mathrm{H}$ & $1: 1$ & 70 \\
\hline lc & $2 c$ & $\mathrm{H}$ & $\mathrm{H}$ & $20: 1$ & 61 \\
\hline
\end{tabular}



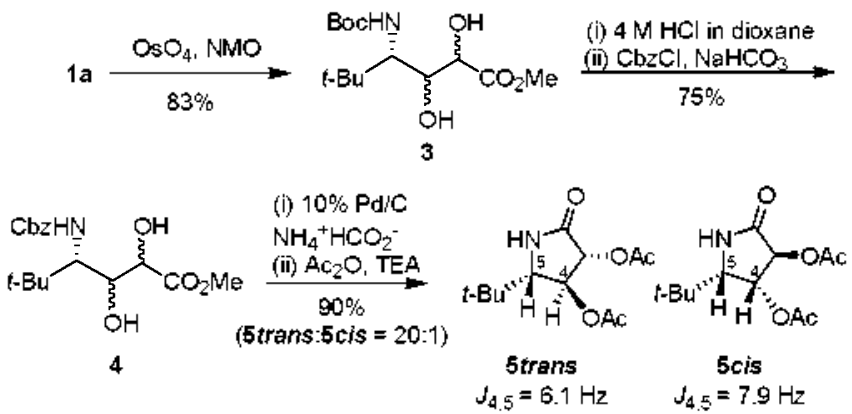

Scheme 1. Assignment of the relative stereochemistry of 2 a

and more than 2 equivalents of $\mathrm{NMO}$ as a co-oxidant and then the crude diol products were acetylated to give diacetates 2a-c. To our excitement. the dilydroxylation reaction of the $\gamma$ amino- $\alpha, \beta$-unsaturated $(E)$-ester 1a showed a ratio of more than 20 to 1 for its anti-isomer on its ${ }^{1} \mathrm{H}$ NMR spectrum. The monosubstituted olefin 1c also resulted in the high antiselectivity. These stereoselective results with a bulky tert-butyl group were quite high compared with those of previously reported results. ${ }^{\text {sa }}$ Especially, the substrate-controlled or chiral agent-controlled dihydroxylations of monosubstituted allylic amines exhibited low and (or) mixed selectivity with a few exceptions. ${ }^{3 a}$ ? On the other hand, the same reaction of $\gamma$ amino- $\alpha . \beta$-unsaturated $(Z$ )-ester 1 b gave a $1: 1$ diastereomeric mixture.

The relative stereochemistry of a mixture of the diol products from la was determined by transformation of the amino diol 3 into the corresponding $\gamma$-lactam derivatives 5 (Scheme 1). The $\mathrm{N}$-Boc group of $\mathbf{3}$ was replaced with the $\mathrm{N}$-Cbz group of 4 in two steps. Then, the $\mathrm{N}$-Cbz protected diol 4 was treated under catalytic hydrogenation conditions to form a lactam ring after removal of the $\mathrm{N}$-Cbz group, which was followed by acetylation to give a diastereomeric mixture of $\gamma$-lactams 5 . The coupling constant $J_{4,5}$ of a major isomer of 5. 5 trans was $6.1 \mathrm{~Hz}$. whereas that of a minor isomer. 5 cis. showed larger value. $7.9 \mathrm{~Hz}$. In general, the $J_{4.5}$ values of $c i s-\gamma-$ lactams are known to be larger than those of trans- $\gamma$ lactams. ${ }^{i \infty 8}$ Therefore the relative stereochemistry of the two hydroxyl groups in the major isomer of 2 a should be anti to the amino group. The anti-selectivity for the diacetates $2 \mathrm{c}$ was also confirmed by measuring the $J_{4,5}$ value $(7.3 \mathrm{~Hz}$ ) of the corresponding oxazolidinone compound derived from the

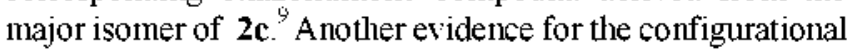
assignment is given below.

The high anti-selectivity exhibited by conjugated $(E)$-ester 1a and the monosubstituted olefin 1c can be rationalized by employing the transition state models proposed by Houk. Kishi and Vedejs (Figure 1). ${ }^{16}$ According to the Houk model. a deactivating substituent such as the $\mathrm{N}$-Boc group would take preferentially the "inside" conformation $\mathbf{A}$ to minimize its orbital overlap with the $C-C$ double bond when the severe $A^{1,3}$ ally lic strain is absent. Addition of $\mathrm{O}_{5} \mathrm{O}_{4}$ from the bottom side of the ' $\mathrm{N}$-inside' conformer would give an anti diol as a major product. When the size of the alkyl group $\mathrm{R}$ is small, the ' $\mathrm{N}$-outside' conformer $\mathrm{B}$ would compete with the ' $\mathrm{N}$-inside' conformer of $\mathbf{A}$, resulting in a reduced anti-selectivity. How-
1) Conjugated $(E)$-ester \& monasubstituted olefin
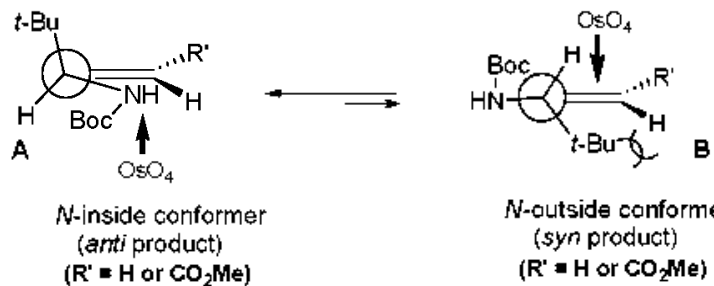

N-outside conformer (syn product) ( $\mathrm{R}^{\prime}=\mathrm{H}$ or $\mathrm{CO}_{2} \mathrm{Me}$ )

2) Conjugated (Z)-ester

t-Bu
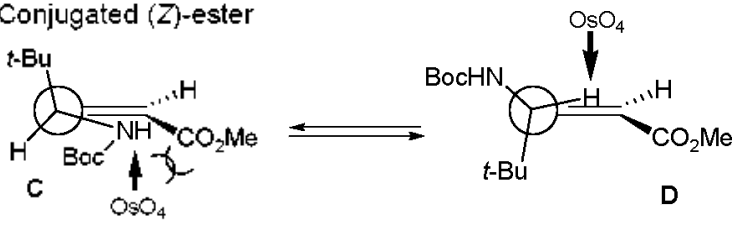

N-inside conformer (antj product)

H-elipsed conformer (syn product)

Figure 1. Probable transition state models.
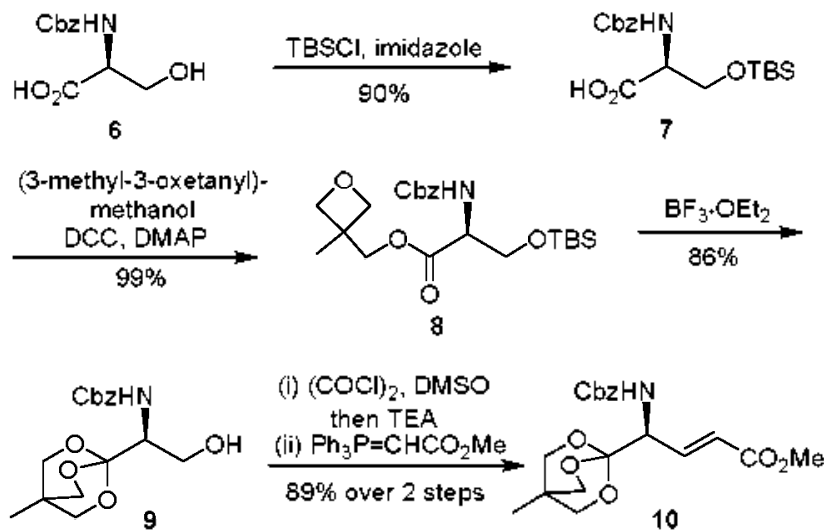

Scheme 2. Preparation of the N-Cbz derivative of $(E)-3,4-$ didehydroglutamate $\mathrm{OBO}$ ester 10.

ever. when $\mathrm{R}$ is a bulky $\boldsymbol{t}$-Bu group, the conformer $\mathbf{B}$ should be strongly disfavored because of the increased repulsive interaction between the $t$ - $\mathrm{Bu}$ group and the double bond. In the case of conjugated (Z)-ester $\mathbf{1 b}$. the $\mathrm{N}$-inside conformer $\mathbf{C}$ would be unfavorable owing to the severe steric hindrance between the methosy carbonyl group and the N-Boc group. Therefore. the conjugated ( $Z$ )-ester $\mathbf{1 b}$ in Table 1 resulted in poor selectivity. The $s m$-selectivity with some $(Z)$-olefins have been reported in literature. . $^{\text {. } .1(k)}$

With the above results in hand, we wanted to apply the diastereoselective dilydroxylation reaction to the conjugated $(E)$-ester 10 with an $\mathrm{OBO}$ ester group in the alkyl chain. Since the OBO ester is a bulky group sinular to the $t-\mathrm{Bu}$ group, a high diastereoselectivity of the dihydroxylation would be expected under the same reaction conditions. Moreover, the $\mathrm{OBO}$ ester group can be readily functionalized to a carboxylic acid or the acid derivatives such as an alcohol or an amine. If the desired high selectivity could be achieved, several interesting bioactive compounds with an amino diol unit would be efficiently prepared. Although the OBO ester group has been utilized for some diastereoselective reactions, it has not been utilized as a stereodirecting group in the $\mathrm{OsO}_{4}$-catal- 
10
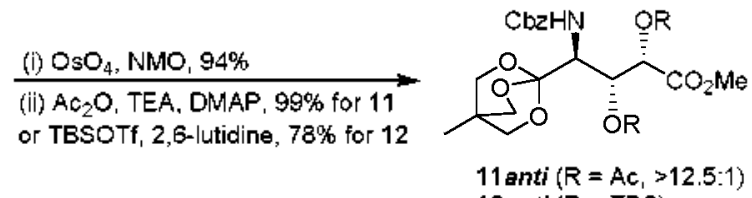

12anti $(R=$ TBS $)$

12

$\frac{10 \% \mathrm{Pd} / \mathrm{C}, \mathrm{NH}_{4}{ }^{+} \mathrm{HCO}_{2}{ }^{-}}{90 \%}$

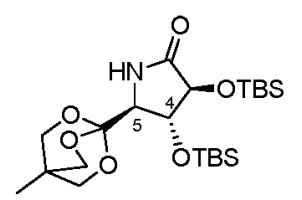

13trans, $J_{4.5}=5.7 \mathrm{~Hz}$

Scheme 3. Dihydroxylation of conjugated $(E)$-ester 10 and determination of the relative stereochemistry.

yzed dilydroxylation reactions to date. ${ }^{11}$

An $\mathrm{X}$-Cbz derivative of $(E)$-3.4-didehydroglutamate $\mathrm{OBO}$ ester 10 was prepared from commercially available $\mathrm{N}$-Cbz-Lserine 6 with a slight modification from the reported procedure (Scheme 2). ${ }^{91}$ After a selective protection of the primary alcohol of 6 with a TBS group, a DCC-mediated coupling of the carboxylic acid of 7 with (3-methyl-3-oxetanyl) methanol produced oxetany lmethyl ester 8 in excellent y ield. The esterification step required only a stoichiometric amount of (3-methyl-3-oxetanyl)methanol. Then compound $\mathbf{8}$ was treated with $\mathrm{BF}_{3} \cdot \mathrm{OEt}_{2}$ to give the $\mathrm{OBO}$ ester functionality of 9 with concomitant deprotection of the TBS group. The above modified procedure for the $\mathrm{OBO}$ ester formation did not require excessive amount of the rather expensive alcohol ${ }^{1 \text { ta }}$ or conversion of the oxetanylalcohol into its tosylate before the esterfication step. ${ }^{11 \mathrm{~b} c \mathrm{c}}$ Moreover. the desired oxetanylmetlyl ester was prepared in higher yield and shorter reaction time. A Swern oxidation of OBO ester 9 followed by a Wittig olefination with the corresponding stabilized ylide provided the desired conjugated (E)-ester 10.

The $\mathrm{OsO}_{4}$-catalyzed dihydroxylation of $\mathbf{1 0}$ was conducted under the same conditions as shown in Scheme 1 (Scheme 3). The resulting amino diol was isolated in $94 \%$ yield but the diastereomeric ratio of the diol product was difficult to be determined because of the some broad peaks in its ${ }^{1} \mathrm{H}-\mathrm{NMR}$ spectnum. After acetylation of the crude diol product. the diastereomeric ratio was shown to be more than $12.5: 1$ by ${ }^{1} \mathrm{H}$ NMR and GC/MS analyses of diacetate 11. To confirm the relative configuration of the new stereogenic centers with the hydroxyl groups, we tried to convert diacetate $\mathbf{1 1}$ into the corresponding $\gamma$-lactam as shown in Scheme 1. However. some unknown side reactions occurred during the cyclization reaction of $\mathbf{1 1}$ to cause a low yield of the corresponding $\gamma$ lactam. Fortunately a cyclization reaction of the TBS-protected amino diol 12 gave only the major isomer of the desired $\gamma$-lactam 13. 13trans. The measured coupling constant $J_{4.5}$ of 13 trans was $5.7 \mathrm{~Hz}$, which indicated that the major isomer was the trans isomer at $\mathrm{C}-4$ and $\mathrm{C}-5$ although the minor isomer of 13 could not be isolated. The $O$-Ac derivative of the major isomer of the $\gamma$-lactam. obtained from 11 as mentioned above, also had the similar $J_{4.5}$ value of $5.8 \mathrm{~Hz}$. An unambiguous assignument of the relative stereochemistry was esta-

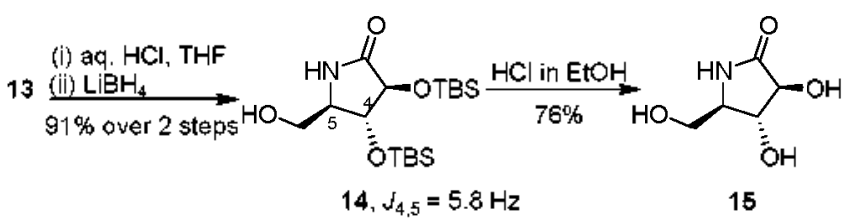

Scheme 4. Synthesis of the target compound 15 from 13 .

blished after conversion of the major isomer of 13 into one of our target compounds 15. a bioactive $\alpha$-glucosidase inhibitor (see below Scheme 4).

It should be noted that the observed selectivity for the $a n t i$ isomer (>12.5:1) in the present study is a much improved result. The reported diastereoselectivities from the $\gamma$-amino- $\alpha$, $\beta$-unsaturated $(E)$-esters with an $X$-Boc or $N$-Cbz group were not consistent and useful. ${ }^{3}$ Especially, the serine-derived $\gamma$ amino- $\alpha . \beta$-unsaturated $(E)$-esters and ketones gave the mixed results ranging from 1:1.9 to $6: 1$ of an antisy ratio. ${ }^{12}$ It is also interesting to note that the selectivity obtained from conpound 10 is comparable to that of the $\gamma$-amino- $\alpha, \beta$-unsaturated $(E)$-ester $($ anti:sm $=13: 1)$ with a 2-ary loxazoline group in the alkyl chain which was possible only with the chiral $\mathrm{AD}$-mix$\beta$ reagent used. ${ }^{12 t}$

The potential applications of the present method are an efficient and highly' stereoselective sy'nthesis of natural and unnatural compounds with an amino diol unit such as 3.4dihydroxyglutamic acid. ${ }^{8_{3}}$ 3.4-di-epi-polyoxamic acid. ${ }^{13} \mathrm{~d}$ iminoarabinitol ${ }^{14}$ and a key structural motif found in sphingosine analogs. ${ }^{15}$ As an example. Scheme 4 shows a straightforward conversion of $\gamma$-lactan 13 into a chiral azasugar 2py rrolidinone 15 , an $\alpha$-glucosidase inhibitor. Thus. the OBO ester group of 13 was hydrolyzed under acidic conditions and then, the resulting ester group was reduced by $\mathrm{LiBH}_{4}$ to afford the primary alcohol of 14 in $91 \%$ yield. Finally deprotection of the TBS groups gave (3S, $+R .5 R)$-3,-4-dihydroxy-5-hydroxymetlyl-2-pyrrolidinone 15. The NMR spectrum and optical rotation value well matched those reported in literature. ${ }^{16}$ Thus. it established unequivocally the relative stereochemistry of 13trans.

In conclusion we have found that the $\mathrm{OsO}_{4}$-catalyzed dilydroxylation reactions of the monosubstituted allylic amine and the $\gamma$-anino- $\alpha, \beta$-unsaturated- $(E)$-esters with a bulky group in the alkyl chain provide a high anti-selectivity even with versatile $\mathrm{N}$-acyloxy protecting groups such as a $\mathrm{N}$-Boc or $\mathrm{N}-\mathrm{Cbz}$ group. The high selectivity was also possible even without addition of chiral agents. Therefore the $\mathrm{OBO}$ ester group in the alkyl chain of the conjugated $(E)$-ester 10 was proved to be a functionalized stereodirecting group in the $\mathrm{OsO}_{4}$-catalyzed dihydroxylations. The potential of the present method was demonstrated by an efficient conversion of the key $\mathrm{N}$-Boc or $\mathrm{N}$-Cbz intermediate $\mathbf{1 2}$ into one of the target compounds 15 , an $\alpha$-glucosidase inhibitor. Its further synthetic applications to other bioactive target compounds are currently underway in our lab.

\section{Experimental Section}

Methyl (2E, $+R)$-4-(tert-butoxycathonyl)amino-5,5-dime- 
thỵlhex-2-enoate (1a). Mp $102-10+{ }^{\circ} \mathrm{C} ;[\alpha]_{\mathrm{D}}^{30}-2.4$ (c 0.70 . $\left.\mathrm{CHCl}_{3}\right):{ }^{\mathrm{H}} \mathrm{H} \mathrm{NMR}\left(400 \mathrm{MHz}, \mathrm{CDCl}_{3}\right) \delta 0.95$ (s. 9H) 1.45 (s. 9H). 3.75 (s. $3 \mathrm{H}) .4 .08-4.14$ (m. lH) 4.62 (br d. IH. $J=9.6$ ). $5.94($ d. 1 H. $J=15.6), 6.97$ (dd. $1 \mathrm{H}, J=15.6 .6 .0):{ }^{13} \mathrm{C} \mathrm{NMR}$ $\left(100 \mathrm{MHz} . \mathrm{CDCl}_{3}\right) \delta$ o 26.2. 28.2. 34.7. 51.4. 59.9.79.4. 121.6 . 146.2. 155.3, 166.5; HRMS (CI) calcd for $\mathrm{C}_{4} \mathrm{H}_{26} \mathrm{NO}_{4}\left(\mathrm{M}^{-}+\mathrm{H}\right)$ 272.1862, found 272.1861

Methyl 4-(tert-butoxycarbonyl)amino-2,3-dihydroxy-5,5dimethylhexanoate (3). To a solution of $(E)$-ester $1 \mathrm{a}(271 \mathrm{mg}$. 1.0 mmole) and NMO (294 mg. $2.5 \mathrm{mmole}$ ) in dry THF (10 $\mathrm{mL}$ ) was added $\mathrm{OsO}_{4}$ ( $25 \mathrm{mg}$. $0.1 \mathrm{mmole}$ ). The resulting mixture was stirred for $8 \mathrm{~h}$ at room temperature and then. the reaction was quenched with a saturated aq. $\mathrm{Na}_{-} \mathrm{SO}_{3}$ solution $(5$ $\mathrm{mL})$. The resulting mixture was extracted with $\mathrm{Et}_{2} \mathrm{O}(20 \times 2)$. The combined organic layers were dried over $\mathrm{MgSO}_{4}$ filtered, and concentrated under reduced pressure. The crude residue was purified by $\mathrm{SiO}_{2}$ column chromatography (Hexane $/ \mathrm{EtOAc}=2: 1)$ to give diol $3(253 \mathrm{mg}, 83 \%,>20: 1$ diastereomeric mixture) as white solid. The major isomer of 3 (3anti-(2R,3S,4S)): $\operatorname{mp~} 103-105^{\circ} \mathrm{C} ;[\alpha]_{\mathrm{D}}^{\circ}-1.0\left(c 0.34 . \mathrm{CHCl}_{3}\right)$ : ${ }^{\mathrm{l}} \mathrm{H} \mathrm{NMR}\left(300 \mathrm{MHz} . \mathrm{CDCl}_{3}\right) \delta 1.04$ (s. 9H). 1.44 (s, 9H), 2.57 (d. 1 H. $J=10.2$ ). 3.53 (dd. 1 H. $J=10.0 .8 .3$ ). 3.80 (d. $1 \mathrm{H}, J=$ $4.6), 3.83(\mathrm{~s}, 3 \mathrm{H}), 4.00$ (dd. $1 \mathrm{H} . J=10.2 .8 .3), 4.40$ (d. $1 \mathrm{H} . J$ =4.6). 4.93 (d. IH. $J=10.0):{ }^{13} \mathrm{C}$ NMR $\left(100 \mathrm{MHz}, \mathrm{CDCl}_{3}\right) \delta$ 27.4. 28.3. 34.2. 52.7, 60.8, 72.2, 72.3, 80.2, 157.3. 173.0: HRMS (CI) calcd for $\mathrm{C}_{14} \mathrm{H}_{2} \mathrm{NO}_{6}\left(\mathrm{M}^{+}+\mathrm{H}\right) 306.1917$. found 306.1917 .

3,4-Diacetoxy-5-tert-butylpy molidin-2-one (5). Diol 4 (120 mg. $0.354 \mathrm{mmole})$ was dissolved in $\mathrm{MeOH}(10 \mathrm{~mL})$, and both $10 \% \mathrm{Pd} / \mathrm{C}(60 \mathrm{mg})$ and $\mathrm{HCO}_{2} \mathrm{NH}_{4}(450 \mathrm{mg}, 7.07 \mathrm{mmol})$ were sequentially added to the solution. The mixture was heated at $65^{\circ} \mathrm{C}$ for $1 \mathrm{~h}$. Then. the reaction mixture was cooled, filtered through a Celite pad followed by rinsing with $\mathrm{Et} \leqslant \mathrm{O}(10 \mathrm{~mL} \times$ 2 ). The combined filtrate and washings were evaporated under reduced pressure. The crude product was dissolved in $\mathrm{DCM}(10 \mathrm{~mL})$ and treated with $\mathrm{Ac}_{2} \mathrm{O}(0.16 \mathrm{~mL}, 1.77 \mathrm{mmole})$. TEA (0.25 $\mathrm{mL}, 1.77 \mathrm{mmole}$ ) and DMAP ( $8 \mathrm{mg}, 0.07 \mathrm{mmole}$ ). The reaction mixture was stirred for $3 \mathrm{~h}$ at room temperature. Then. the reaction was quenched with a $10 \%$ aq. $\mathrm{NaHCO}_{3}$ solution ( $10 \mathrm{~mL}$ ). The aqueous layer was extracted with DCM $(10 \mathrm{~mL} \times 2)$. The combined organic layers were dried over $\mathrm{MgSO}_{4}$. filtered. and concentrated under reduced pressure. The crude residue was purified by $\mathrm{SiO}_{2}$ column chromatography (hexane/EtOAc $=1: 1)$ to give diol $5(82 \mathrm{mg}$. 90\%. 20:1 diastereomeric mixture) as waxy solid. The major isomer of $5(5$ trans- $(3 R,+S, 5 S)):[\alpha]_{D}^{0(1}-20.1\left(c 0.76, \mathrm{CHCl}_{3}\right) .{ }^{1} \mathrm{H} \mathrm{NMR}$ $\left(300 \mathrm{MHz} \mathrm{CDCl}_{3}\right) \delta 0.94(\mathrm{~s}, 9 \mathrm{H}), 2.08$ (s. $\left.3 \mathrm{H}\right) .2 .15$ (s. $\left.3 \mathrm{H}\right)$. 3.39 (dd. $1 \mathrm{H} . J=6.1 .1 .0) .5 .37$ (t. IH. $J=6.1$ ). 5.45 (d. lH. $J$ =6.1). 6.93 (br 5, 1H): ${ }^{13} \mathrm{C}$ NMR (75 MHz. $\left.\mathrm{CDCl}_{3}\right)$ ò 20.5 . $20.7 .25 .3 .32 .9 .64 .3 .73 .6 .75 .5,169.7,169.9 .170 .1$ : HRMS (CI) calcd for $\mathrm{C}_{12} \mathrm{H}_{2}\left(\mathrm{NO} \mathrm{NO}_{5}\left(\mathrm{M}^{+}+\mathrm{H}\right) 258.1341\right.$, found 258.1342 . The minor isomer of $\mathbf{5}(\mathbf{5}$ cis- $(\mathbf{3 S}, \mathbf{4} \boldsymbol{R}, \boldsymbol{5} \boldsymbol{S}))$; ${ }^{1} \mathrm{H}$ NMR $(300 \mathrm{MHz}$. $\mathrm{CDCl}_{3}$ ) ô 1.01 (s. 9H). 2.13 (s. $\left.3 \mathrm{H}\right), 2.18$ (s.3H). $3.5+$ (d. $1 \mathrm{H}$. $J=7.9), 5.58(\mathrm{t}, 1 \mathrm{H}, J=7.9) .5 .72(\mathrm{~d} .1 \mathrm{H}, J=7.9), 6.38$ (br s, 1H).

Methyl 4-(4-methyl-2,6,7-trioxabicyclo[2.2.2]octan-1-y])4-(benzyloxycarbonyl)amino-2,3-diacetoxybutanoate (11). To a solution of $(E)$-ester $10(95 \mathrm{mg} .0 .252 \mathrm{mmol}$ ) and NMO (74 $\mathrm{mg}, 0.629 \mathrm{numol})$ in dry THF $(5 \mathrm{~mL})$ was added $\mathrm{OsO}_{4}(7 \mathrm{mg}$. $0.025 \mathrm{mmol}$ ). The resulting mixture was stirred for $8 \mathrm{~h}$ at room temperature. The reaction was quenched with a saturated aqueous $\mathrm{Na}_{2} \mathrm{SO}_{3}$ solution $(5 \mathrm{~mL}$ ), and the aqueous layer was extracted by $\mathrm{Et}_{2} \mathrm{O}(10 \mathrm{~mL} \times 4)$. The combined organic layers were dried over $\mathrm{MgSO}_{4}$. filtered. and evaporated under reduced pressure. The crude diol could be purified by silica gel column chromatography (hexane/EtOAc $=1: 1$ ) to give a diastereomeric mixture of the diol product ( $97 \mathrm{mg}, 94 \%$ ) as waxy oil. For the in-situ acetylation, the crude diol product was dissolved in DCM (10 nL) followed by addition of $\mathrm{Ac}_{2} \mathrm{O}$ $(0.12 \mathrm{~mL}, 1.26 \mathrm{mmole})$. TEA $(0.18 \mathrm{~mL}, 1.26 \mathrm{mmol})$ and DMAP (4 ng, $0.03 \mathrm{mmole}$ ). After $3 \mathrm{~h}$ at room temperature, the reaction was quenched with a saturated aqueous $\mathrm{NaHCO}_{3}$ solution $(10 \mathrm{~mL})$. The resulting mixture was then extracted with $\mathrm{Et}_{2} \mathrm{O}(10 \mathrm{~mL} \times 2)$. The combined organic layers were dried over $\mathrm{MgSO}_{4}$. filtered and concentrated under reduced pressure. The crude residue was purified by silica gel colunun chromatography (hexane/EtOAc $=2: 1)$ to give $11(117 \mathrm{mg}$. $99 \%$ ) as waxy solid (> 12.5:1 diastereomeric mixture). The major isomer of $11(11$ anti $-(2 S, 3 R,+S)) ;{ }^{l} \mathrm{H} \mathrm{NMR}(300 \mathrm{MHz}$, $\left.\mathrm{CDCl}_{3}\right) \delta 0.79$ (s. $\left.3 \mathrm{H}\right) .1 .97$ (s, 3H). 2.19 (s. $\left.3 \mathrm{H}\right), 3.72(\mathrm{~s} .3 \mathrm{H})$. $3.88(\mathrm{~s}, 6 \mathrm{H}) .4 .41$ (dd, $1 \mathrm{H} . J=10.7,6.6 \mathrm{~Hz}) .5 .05$ (d. $1 \mathrm{H} . J=$ $12.3 \mathrm{~Hz}) .5 .13(\mathrm{~d}, 1 \mathrm{H}, J=12.3 \mathrm{~Hz}) .5 .15(\mathrm{~d}, 1 \mathrm{H}, J=10.7 \mathrm{~Hz})$. $5.56(\mathrm{~d}, 1 \mathrm{H} . J=2.2 \mathrm{~Hz}), 5.68(\mathrm{dd}, 1 \mathrm{H}, j=6.6,2.2 \mathrm{~Hz}):{ }^{13} \mathrm{C}$ NMR (75 MHz, $\left.\mathrm{CDCl}_{3}\right) \hat{\delta}$ 14. 1. 20.5. 20.6, 30.5. 52.5. 54.0. $66.9,68.7,71.8,72.6,107.3,127,9,128.0,128.4,136.3$, 156.2, 167.8, 169.3. 169.8; HRMS (EI) calcd for $\mathrm{C}_{23} \mathrm{H}_{2} \mathrm{NO}_{11}$ (M) 495.1741. found 495.1740.

Methyl 4-(4-methyl-2,6,7-trioxabicyclo[2.2.2]octan-1-yl)+-(benzyloxycarbonyl)amino-2,3-di(tert-butyldimethylsilyloxy)butanoate (12). The crude anino diol $(610 \mathrm{mg}, 1.48$ nimol) obtained from the $\mathrm{OsO}_{4}$-catalyzed dihydrosylation reaction of $(E)$-ester 10 as mentioned above was dissolved in dry DCM $(20 \mathrm{~mL})$ followed by addition of TBSOTf $(0.74 \mathrm{~mL}$, $3.26 \mathrm{mmol})$ and 2.6 -lutidine $(0.69 \mathrm{~mL} .5 .93 \mathrm{mmol})$ at $0{ }^{\circ} \mathrm{C}$ under nitrogen atmosphere. After 30 min the reaction mixture was warmed to room temperature and stirred for another $\mathrm{l} h$. The reaction was quenched by a saturated aqueous $\mathrm{NaHCO}_{3}$ solution ( $15 \mathrm{~mL}$ ) and then. the resulting mixture was extracted with DCM $(20 \mathrm{~mL} \times 2)$. The combined organic layers were dried over $\mathrm{MgSO}_{4}$. filtered, and concentrated under reduced pressure. The cnude residue was purified with silica gel column chromatography (hexane/EtOAc $=2: 1$ ) to give 12 $(0.739 \mathrm{~g} .78 \%)$ as white solid. The major isomer of 12 (12anti$\left.(2 S, 3 R,+S)): \operatorname{mp~} 138-140^{\circ} \mathrm{C}:[\alpha]\right]^{\prime}+0.64(c 0.62, \mathrm{EtOAc}):{ }^{1} \mathrm{H}$ NMR $\left(400 \mathrm{MHz} . \mathrm{CDCl}_{3}\right)$ ô $-0.09(\mathrm{~s}, 3 \mathrm{H}) .0 .04(\mathrm{~s} .3 \mathrm{H}), 0.06$ (s. $3 \mathrm{H}), 0.10$ (s. 3H), 0.80 (s. 12H). 0.93 (s. 9H). 3.68 (s. 3H), $3.91(\mathrm{~s}, 6 \mathrm{H}) .4 .11(\mathrm{dd}, 1 \mathrm{H}, J=9.4 .4 .6 \mathrm{~Hz}), 4.39(\mathrm{dd} .1 \mathrm{H}, J=$ $4.6 .1 .2 \mathrm{~Hz}), 4.79(\mathrm{~d}, \mathrm{lH}, J=1.2 \mathrm{~Hz}) .5 .03$ (d. $1 \mathrm{H}, J=12.4$ Hz). 5.09 (d. IH. $J=12.4 \mathrm{~Hz}$ ). 6.20 (d. lH. $J=9.4$ ). 7.28-7.32 (m. $5 \mathrm{H}):{ }^{13} \mathrm{C}$ NMR $\left(100 \mathrm{MHz}, \mathrm{CDCl}_{3}\right) \delta-5.59$. -4.90, -4.58, $-4.47,14.4,17.7,18.3,25.4 .25 .8,30.5,51.5,59.0 .66 .3,68.9$, $72.4,75.0 .107 .9 .127 .4,127.7,128.1,136.9,156.9$. 172.5; HRMS (CI) calcd for $\mathrm{C}_{31} \mathrm{H}_{53} \mathrm{NO}_{9} \mathrm{Si}_{2}\left(\mathrm{M}^{-}+\mathrm{H}\right) 640.3339$. found 640.3337 .

$(3 S,+R, 5 S)-5-(4-M e t h y l-2,6,7-$ trioxabicyclo[2.2.2]0ctan-1yl)-3,4-bis(tert-butyldimethylsilyloxy )pymlidin-2-one 
(13trans). To a solution of $12(590 \mathrm{mg}, 0.922 \mathrm{mmol})$ in EtOAc $(25 \mathrm{~mL})$ were added $\mathrm{HCO}_{-} \mathrm{NH}_{4}(1.18 \mathrm{~g} .18 .8 \mathrm{mmol})$ and 10 $w t \% \mathrm{Pd} / \mathrm{C}$ (300 mg). The resulting mixture was heated to reflux for $1 \mathrm{~h}$. After the reaction was completed, the reaction mixture was filtered through a Celite pad and rinsed with EtOAc $(20 \mathrm{~mL} \times 2)$. Then the solvent was evaporated under reduced pressure. The residue was purified with silica gel column chromatography (hexane/EtOAc $=2: 1$ ) to give only the major isomer of $\gamma$-lactam 13 (13trans. $39+\mathrm{mg} .90 \%$ ) as white solid. The minor isomer of 13 (13cis) was scarcely detected and not isolable. Mp $135-137^{\circ} \mathrm{C}:[\alpha]_{\mathrm{D}}^{\mathrm{D} D}-8.3\left(\mathrm{c} 0.68^{\circ}\right.$. EtOAc): ${ }^{1} \mathrm{H}$ NMR (300 MHz. $\left.\mathrm{CDCl}_{3}\right)$ ò 0.09 (s. 3H). 0.11 (s. $3 \mathrm{H}), 0.14$ (s. $3 \mathrm{H}), 0.19(\mathrm{~s}, 3 \mathrm{H}), 0.82(\mathrm{~s}, 3 \mathrm{H}), 0.89$ (s. $9 \mathrm{H}) .0 .92$ (s. $9 \mathrm{H}$ ). 3.38 (d. $1 \mathrm{H}, J=5.7 \mathrm{~Hz}$ ). 3.90 (s. $6 \mathrm{H}$ ). 4.16 (dd. $1 \mathrm{H} . J$ $=5.7,1.0 \mathrm{~Hz})+4.35(\mathrm{t} .1 \mathrm{H}, J=5.7 \mathrm{~Hz}), 5.66(\mathrm{~s} . \mathrm{HH}):{ }^{19} \mathrm{C} \mathrm{NMR}$ $\left(75 \mathrm{MHz} \mathrm{CDCl}_{3}\right) \delta$-4.7. -4.5. -4.1. $-3.8,14.3 .17 .9,18.3$. $25.8 .26 .0,30.7,61.5,72.5,76.4 .78 .5,106.9,172.8$. HRMS (CI) calcd for $\mathrm{C}_{2} \mathrm{H}_{44} \mathrm{NO}_{6} \mathrm{Si}_{2}\left(\mathrm{M}^{-}+\mathrm{H}\right)+74.2707$. found $47+2705$.

$(3 S,+R, 5 R)-5-H y d$ loxymethyl-3,4-bis(tert-butyldimethylsilyloxy)pymolidin-2-one (14). To a solution of 13trans (794 mg. $1.68 \mathrm{mmol}$ ) in THF (20 mL) was added an aqueous $\mathrm{HCl}$ solution (1 M. $0.2 \mathrm{~mL}$ ) at room temperature. After stirring for $\mathrm{l} h$. the reaction solvent was evaporated under reduced pressure. The crude product was dissolved in dry THF (20 $\mathrm{mL})$ and then $\mathrm{LiBH}_{4}(2.5 \mathrm{~mL} .2 .0 \mathrm{M}$ in THF) was added to the reaction mixture at $0{ }^{\circ} \mathrm{C}$. After $1.5 \mathrm{~h}$. the reaction was quenched by a saturated aqueous $\mathrm{NH}_{4} \mathrm{Cl}$ solution ( $10 \mathrm{~mL}$ ). Then the resulting mixture was extracted with $\mathrm{Et}_{2} \mathrm{O}(25 \mathrm{~mL} \times 2)$. The combined organic layers were dried over $\mathrm{MgSO}_{4}$. filtered and concentrated under reduced pressure. The residue was purified with silica gel column chromatography (hexane/ EtOAc $=2: 1)$ to give $14(573 \mathrm{mg}, 91 \%)$ as white solid. $\mathrm{Mp}$ $112-114^{\circ} \mathrm{C}:[\alpha]^{2}{ }_{\mathrm{D}}^{\mathrm{D}}+0.82\left(\mathrm{c} 0.34\right.$. EtOAc): ${ }^{1} \mathrm{H} \mathrm{NMR}(400 \mathrm{MHz}$. $\left.\mathrm{CDCl}_{3}\right) \delta 0.10$ (s.3H). $0.11(\mathrm{~s}, 3 \mathrm{H}), 0.14$ (s. $\left.3 \mathrm{H}\right), 0.19(\mathrm{~s}, 3 \mathrm{H})$, 0.89 (s. 9H). 0.92 (s. 9H). 2.92 (t. IH. $J=5.7 \mathrm{~Hz}$ ). 3.39-3.44 (m, $1 \mathrm{H}), 3.54-3.60$ (m. $1 \mathrm{H}) .3 .78-3.84$ (ddd, $1 \mathrm{H}, J=11.9 .5 .8$, $3.2 \mathrm{~Hz}$ ) 4.00 (t. IH. $J=5.8 \mathrm{~Hz}$ ) 4.15 (d. $1 \mathrm{H}, J=5.8 \mathrm{~Hz}$ ). $6.5 \mathrm{I}$ (s. 1H): ${ }^{13} \mathrm{C}$ NMR $\left(75 \mathrm{MHz}, \mathrm{CDCl}_{3}\right) \delta-4.5,-4.4,-4.0,-3.9$. 18.0. 18.4, 25.9, 26.0. 60.6, 62.7, 76.9. 78.0. 174.5; HRMS (CI) calcd for $\mathrm{C}_{1}-\mathrm{H}_{38} \mathrm{NO}_{4} \mathrm{Si}_{2}\left(\mathrm{M}^{-}+\mathrm{H}\right) 376.2339$. found 376.2341 .

(3S,+R,5R)-3,+-Dihydroxy-5-(hydroxymethyl)pynolidin2-one (15). $\gamma$-Lactam 14 (100 $\mathrm{mg}$. $0.266 \mathrm{mmole}$ ) was dissolved in EtOH ( $5 \mathrm{~mL}$ ) and an aqueous $\mathrm{HCl}$ solution $(6 \mathrm{M}$. $2 \mathrm{~mL}$ ) was added to the solution at room temperature. The resulting mixture was stirred for $2 \mathrm{~h}$. After the reaction was completed. the solvent was evaporated under reduced pressure. Then, the crude product was dissolved in $\mathrm{Et}_{2} \mathrm{O}(10 \mathrm{~mL})$ followed by addition of $\mathrm{H}_{2} \mathrm{O}(10 \mathrm{~mL})$, and the phases were separated. The aqueous layer was evaporated under reduced pressure to give the product $15(30 \mathrm{mg}$. $76 \%$ ) as white solid. Mp 135-137 ${ }^{\circ} \mathrm{C}:[\alpha] \overline{\mathrm{D}}+15.4\left(c 0.72 . \mathrm{H}_{2} \mathrm{O}\right):{ }^{1} \mathrm{H}$ NMR $\left(\mathrm{D}_{2} \mathrm{O}\right) \dot{\delta}$ $3.39-3.44$ (m. 1H). 3.57 (dd. $1 \mathrm{H} . J=12.3,4.8 \mathrm{~Hz}$ ). 3.75 (dd. IH. $J=12.3 .3 .0 \mathrm{~Hz}$ ) 3.97 (t. $\mathrm{IH} . J=7.8 \mathrm{~Hz}) .4 .27$ (d. IH. $J$ $=7.8 \mathrm{~Hz}):{ }^{13} \mathrm{C}$ NMR $\left(\mathrm{D}_{2} \mathrm{O}\right) \delta 58.7 .60 .7,75.3 .76 .3,176.2$ : HRMS (CI) calcd for $\mathrm{C}_{5} \mathrm{H}_{10 \mathrm{NO}_{4}}\left(\mathrm{M}^{-}+\mathrm{H}\right)$ 148.0611. found 148.0610
Aclonowledgments. We thank the BK 21 Progran and Agency for Defence Development of Korea for financial support. This work was also supported in part by Samsung Electronics Manufacturing Technology Team and KOSEF through Research Center for Energy Conversion and Storage

\section{Refeiences}

1. (a) Ager, D. J.: Prakash, I.; Schald, D. R. Chem Rev 1996, 96 , 835. (b) Bergmeier, S. C. Tetwhedron 2000, 56, 2561. (c) Enders, D; Paleček, T.; Grondal, C. Chem. Commthn. 2006, 655.

2. (a) Oh, I. S.; Hong. Y. S.; Kim, Y. G. J. Ind Eng. Chem 1997, 3 , 326 [Chem. Abs 1998, 129, 202696z]. (b) Donohoe, T. T.; Blades, K.; Moore, P. R.: Waring, M. J.: Winter, J. J. G.; Helliwell, M.; Newcombe, N. J.; Stemp, G. J. Org. Chem. 2002, 67,7946.

3. (a) For reviews, see: Cha, T. K.; Kim, N.-S. Chem. Rev. 1995, 95 , 1761. (b) Dee, M. F.: Rosati, R. L. Bioong. Med. Chem. Lett. 1995, 5, 949. (c) Reetz, M. T.: Strack, T. J.: Mutulis, F.: Goddard. R. Tetrahedron Lett 1996, 37, 9293. (d) Azuma, H.; Tamagaki, S.: Ogino, K. J. Org. Chem 2000, 65, 3538. (e) Dolle, R. E.; Herpin, T. F.; Shimshock, Y. C. Tetrahedron Lett. 2001, 42, 1855. (f) Kotkar, S. P.; Chavan, V. B.; Sudalai, A. Oig. Letr. 2007, 9, 1001. (g) Reddy, J. S.; Rao, B. V. J. Org. Chent. 2007, 72,2224

4. (a) Matsulua, F.: Hamada, Y.; Shioiri, T.; Tetrahedron Lett. 1994, 35, 733. (b) Trost, B. M.; Krueger, C.: Bunt, R. C.; Zambrano, I. J. Am. Chem. Soc. 1996, 118,6520. (c) Imashiro, R.; Sakurai, O.; Yamashita, T; Horikawa, H. Tetrohed $w$ 1998, 54, 10657 . (d) Broady, S. D.; Rexhausen, J. E; Thomas, E. T. J. Chem. Soc., Pewin Trans. I 1999, 1083. (e) Shirota, O.; Nakanishi, K.: Berova, N. Tetrahedron 1999, 55, 13643. (f) Thoen, J. C. Morales-Ramos, A. I.; Lipton, M. A. Org. Lent. 2002, 4, 4455. (g) Yang, G.; Schmieg, T.; Tsuji, M.; Franck, R. W. Angew. Chem. Int Ed. 2004, 43, 3818. (h) Coutrot, P: Claudel, S.: Didierjean, C.: Grison, C. Bioorg. Med. Chem. Lett. 2006, 16, 4 17. (i) Shuter, E. C.; Duong, H.; Hutton, C. A.; McLeod, M. D. Org. Biomol Chent 2007, 5,3183 .

5. (a) On, T. S.: Park, D. Y.: Song, B. S.: Bae, I. G.: Yoon, S. W; Kim, Y. G. Tetrahedron Letr. 2002, 43, 7209 and references therein. (b) Oh, I. S.: Jeon, I.; Park, D. Y.; Kim, Y. G. Chem. Conmun 2005, 770. (c) Jeon. J.; Honng, S.-K, Oh, J. S, Kim, Y. G. J. Org. Chemt 2006, 71, 3310. (d) Jeon, T.; Lee, J. H.; Kim, I.-W; Kim, Y. G. Tetrahedron: Asymmetry 2007, 18, 2448.

6. Teon, T.; Shin, M: Yoo, J. W.: Oh, J. S.: Bae, I. G.; Jung, S. H.: Kim. Y. G. Tetwhedron Lett. 2007, $48,1105$.

7. (a) Pirrung, M. C; Num, D. S.; McPhail, A. T. Bioorg. Med. Chem. Lett. 1993, 3, 2095. (b) Olsen. T. A.; Severinsen, R.; Rasmussen, T. B.; Hentzer, M.; Givskov, M:- Nielsen, J. Biooig. Hed. Chem. Lett 2002, 12, 325.

8. (a) Oba, M; Koguchi, S.; Nishiyana, K. Tetwhedron 2002, 58 , 9359. (b) The $J_{1.5}$ values of the trans $\gamma$-lactams with different side alkyl groups (Me, Bn, i-Bu and $\mathrm{i}-\mathrm{Pr}$ ) showed ca. $6.0 \mathrm{~Hz}$, whereas the larger $J_{t .5}$ values of $7.1-7.5 \mathrm{~Hz}$ were observed with the cis $\gamma$ lactams. Oh, J. S. Ph. D. Dissertation, Seoul National University, Seoul, Republic of Korea, 2004.

9. The larger coupling constant of $7.3 \mathrm{~Hz}$ in oxazolidinones is generally attributed to the cis oxazolidinone structure (ref. $5(a)$ and references therein).

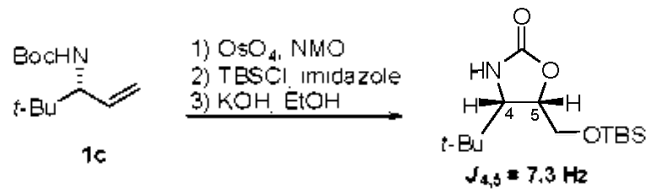

10. (a) Houk, K. N.; Duh, H.-Y; Wu, Y.-D; Moses, S. R. J. Am. Chent. Soc. 1986, 108, 2754. (b) Cha, J. K, Christ, W. J.; Kishi, 
Y. Tetrahedron Lett. 1983, 24, 3943 and 3947 , (c) Vedejs, E.: McClure, C. K. J. Am. Chem. Soc. 1986, 108, 1094. (d) Krysan, D. I.; Rockway, T. W.: Haight, A. R. Tetrahedron: Asmmetry $1994,5,625$

11. (a) Blaskovich, M. A.: Lajoie, G. A. J. An. Chent. Soc. 1993 115,5021 . (b) Blaskovich, M. A.; Evindar, G.; Rose, N. G. W. Wilkinson, S.; Luo, Y.; Lajoie, G. A. J. Org. Chem. 1998, 63, 3631. (c) Hansen, D. B.; Wan, X.; Carroll, P. J; Joullié, M. M. J. Org. Chent. 2005, 70, 3120. (d) Hansen, D. B.; Lewis, A. S.; Gavalas, S. J.: Ioullie, M. M. Tetrahedron: Asmmetry 2006, 17, 15 .

12. (a) Dondoni, A:; Merino, P.; Perrone, D. Tetwhedron 1993, t9, 2939. (b) Huang, Y; Carroll, P. J.; Dalton, D. R. J. Org. Chent. $1997,62,372$. (c) Hulne, A. N.: Montgomery, C. H. Tetr- ahedron Lett. 2003, 44, 7649. (d) Shinada. T.; Ikebe, E.: Oe, K.; Namba, K.: Kawasaki, M: Ohfune, Y. Org. Lett. 2007,9, 1765. 13. Li, S.; Hui, X.-P.; Yang. S.-B.; Jia, Z.-I.: Xu, P.-F.; Lu, T.-I. Tetrahe dron: Astmmetry 2005, 16, 1729.

14. Hulme, A. N.; Montgomery, C. H.; Henderson, D. K. J. Chem. Soc., Perlin Trans $12000,1837$.

15. (a) Raghavan. S.: Rajender. A. J. Ong. Chem. 2003.68, 7094. (b) Lu, X.; Byun, H.-S.; Bittman, R. J. Org. Chem. 2004, 69, 5433. (c) Ha, H.-T; Yoon, D.-H.; Kang, L.-S.; Hong, M. C.; Lee, W. K. Bull. Korean Chem. Soc. 2009, $30,535$.

16. (a) Kayakiri, H.: Nakamura, K.: Takase, S.: Setoi, H.: Uchida, I.: Terano, H: Hashimoto, M.; Tada, T; Koda, S. Chem. Pham. Bull. 1991, 39, 2807. (b) Kim, Y. T.; Takatsuki, A.; Kogoshi, N.; Kitahara, T. Tetrahedron, $1999,55,8353$. 